\title{
Assessing the contextual effect of community in the utilization of postnatal care services in Ghana
}

\author{
Emmanuel Dankwah', Cindy Feng ${ }^{1,2}$, Shelley Kirychuck ${ }^{3}$, Wu Zeng ${ }^{4}$, Rein Lepnurm ${ }^{1}$ and Marwa Farag ${ }^{1,5^{*}}$ (D)
}

\begin{abstract}
Background: Inequalities in the use of postnatal care services (PNC) in Ghana have been linked to poor maternal and neonatal health outcomes. This has ignited a genuine concern that PNC interventions with a focus on influencing solely individual-level risk factors do not achieve the desired results. This study aimed to examine the community-level effect on the utilization of postnatal care services. Specifically, the research explored clusters of non-utilization of PNC services as well as the effect of community-level factors on the utilization of PNC services, with the aim of informing equity-oriented policies and initiatives.
\end{abstract}

Methods: The 2014 Ghana Demographic and Health Survey GDHS dataset was used in this study. Two statistical methods were used to analyze the data; spatial scan statistics were used to identify hotspots of non-use of PNC services and second two-level mixed logistic regression modeling was used to determine community-level factors associated with PNC services usage.

Results: This study found non-use of PNC services to be especially concentrated among communities in the Northern region of Ghana. Also, the analyses revealed that community poverty level, as well as community secondary or higher education level, were significantly associated with the utilization of PNC services, independent of individual-level factors. In fact, this study identified that a woman dwelling in a community with a higher concentration of poor women is less likely to utilize of PNC services than those living in communities with a lower concentration of poor women (Adjusted odds ratio (AOR) $=0.60,95 \% \mathrm{Cl}$ : $0.44-0.81$ ). Finally, $24.0 \%$ of the heterogeneity in PNC services utilization was attributable to unobserved community variability.

Conclusion: The findings of this study indicate that community-level factors have an influence on women's healthseeking behavior. Community-level factors should be taken into consideration for planning and resource allocation purposes to reduce maternal health inequities. Also, high-risk communities of non-use of obstetric services were identified in this study which highlights the need to formulate community-specific strategies that can substantially shift post-natal use in a direction leading to universal coverage.

Keywords: Postnatal care, Contextual effect, Community, Utilization

\footnotetext{
* Correspondence: marwa.farag@usask.ca; marwa.farag@dohainstitute.edu.qa

'School of Public Health, University of Saskatchewan, 104 Clinic Place,

Saskatoon, SK S7N 2Z4, Canada

${ }^{5}$ School of Public Administration and Development Economics, Doha

Institute for Graduate Studies, Al Tarfa Street, Zone 70, Doha, Qatar

Full list of author information is available at the end of the article
}

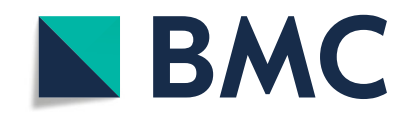

(c) The Author(s). 2021 Open Access This article is licensed under a Creative Commons Attribution 4.0 International License, which permits use, sharing, adaptation, distribution and reproduction in any medium or format, as long as you give appropriate credit to the original author(s) and the source, provide a link to the Creative Commons licence, and indicate if changes were made. The images or other third party material in this article are included in the article's Creative Commons licence, unless indicated otherwise in a credit line to the material. If material is not included in the article's Creative Commons licence and your intended use is not permitted by statutory regulation or exceeds the permitted use, you will need to obtain permission directly from the copyright holder. To view a copy of this licence, visit http://creativecommons.org/licenses/by/4.0/ The Creative Commons Public Domain Dedication waiver (http://creativecommons.org/publicdomain/zero/1.0/) applies to the data made available in this article, unless otherwise stated in a credit line to the data. 


\section{Background}

The post-natal period is a critical stage in the obstetric cycle, especially, the first $24 \mathrm{~h}$ and early days following childbirth $[1,2]$. Women and babies need special attention during this period because most deaths occur in that time [3]. Moreover, studies have found that adequate care during the post-partum period is vital for maternal and child survival, especially in poorer regions of the world with high maternal and neonatal mortalities $[4,5]$. Researchers contend that achieving a post-natal care (PNC) services utilization rate of $90 \%$ in Africa could save between 10 to $27 \%$ of neonatal deaths [2].

Despite the benefits derived from PNC services, a large proportion of sub-Saharan Africa mothers and babies especially those that delivered outside health facility do not use post-natal services [6]. Ghana is a western African country that spans a land area of $238,535 \mathrm{~km}^{2}$ [7] and shares boundary with Burkina Faso to the north, Cote d'Ivoire to the west, Togo to the east and the Gulf of Guinea on the south (Fig. 1). Ghana had 10 administrative regions during the 2014 Ghana Demographic and Health Survey (GDHS) namely Western, Central, Greater-Accra, Volta, Eastern, Ashanti, Brong Ahafo, Northern, Upper East and Upper West (Fig. 1). The situation is not different in Ghana, a nation with a fertility rate of 4 and approximately $76 \%$ livebirths from all pregnancies [7]. A critical mass of mothers and newborns lack needed PNC services [7, 8]. A previous study conducted in one administrative region of Ghana reported that PNC services covered $43.8 \%$ of mothers [8] whereas another study revealed that $56 \%$ of neonates immediately received PNC services within $48 \mathrm{~h}$ after their birth [9] in Ghana. Such underutilization and discrepancies in the usage of postdelivery services exposes mother and

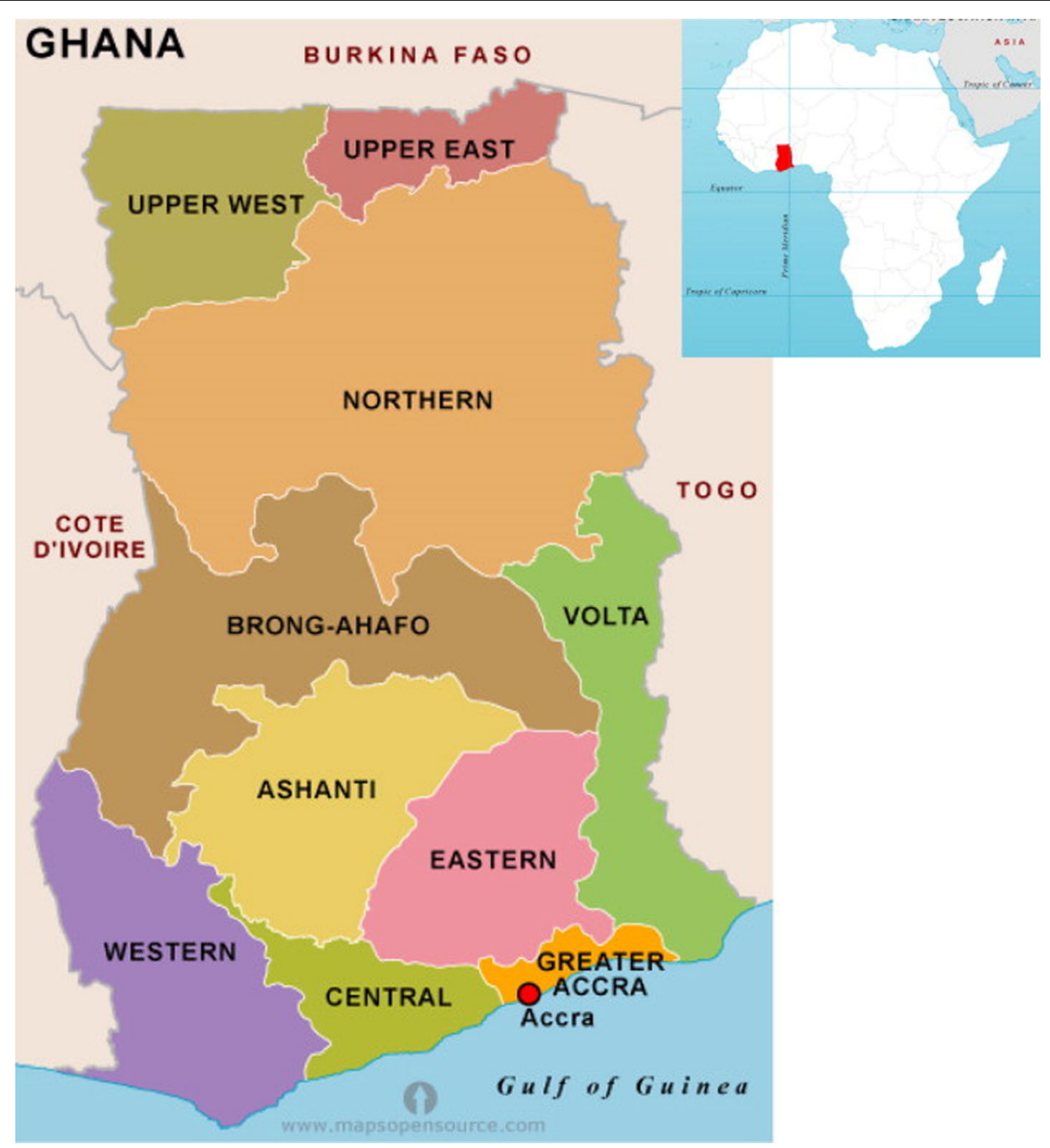

Fig. 1 ap of Ghana and its location in Africa. Source: http://www.mapsopensource.com 
newborn to higher risk of morbidity and mortality [10], as well as undermining healthy behaviors and practices such as exclusive breastfeeding and uptake of family planning [1].

It is manifestly clear that identifying determinants of PNC service utilization are necessary to guide public health interventions. Most studies on the usage of PNC services are concentrated on identifying individual-level factors [11-15]. Although evidence exists at the individual-level that PNC services utilization is associated with socioeconomic predictors [13, 16-19], there is a general concern that PNC interventions focused solely on influencing individual-level risk factors do not achieve the desired results. For this reason, recent studies considered community-level effects [20,21], but the results were mixed. For instance, Worku et al. [22] found no significant area-level effects on the use of PNC services. Some multilevel studies in Tanzania [23], Nigeria [24], Zambia [25], Kenya [26] and India [27, 28] reported that a community-level effect strongly predicted PNC services use, after controlling for individuallevel predictors. In addition, these previous studies estimated different community-level effects of communities on the utilization of PNC services; for example Mohan et al. [23] and Solanke et al. [29] reported that 12 and $37.2 \%$ unexplained community variance respectively accounted for the variability in PNC services use. Many methodological limitations accompanied these contradictory findings including the use of a limited number of independent variables and inadequate adjustment for confounding.

Likewise, inequalities in the use of PNC services across communities have been observed in Ghana [7]. However, research about the utilization of PNC services in Ghana is scanty $[8,30]$. In addition, most of the studies were restricted to a specific geographical area of the country which seriously affects the potential for extrapolation of findings to the entire population $[8,30]$. A thorough literature review indicated that communitylevel effects on variation in the use of PNC services in Ghana remain uncertain. The review showed that the majority of studies conducted in Ghana used only individual-level data [12]. Hence, there is a dearth of evidence measuring the association between communitylevel risk factors and the utilization of PNC services specific to Ghana. This study intends to assess (1) the community-level effect on the utilization of PNC services in Ghana using a multilevel regression model with a logit link function and (2) explore the spatial pattern of non-use of PNC services across Ghanaian communities. The findings from this study could be used to inform equity-based interventions to improve the use of PNC services across communities in Ghana and other low-income countries.

\section{Methods}

Data source: Ghana demographic health survey (2014GDHS)

This research used the 2014 Ghana Demographic and Health Survey (GDHS) dataset. The Demographic and Health Survey (DHS) program has a long-standing reputation for the collection, processing and sharing of population and health information in over 90 low-and lowermiddle-income countries, including Ghana. The 2014 GDHS was conducted in Ghana by Ghana Statistical Services, Ghana Health Services and the National Public Health Laboratory with technical support from the Inner City Fund (ICF) international.

According to the 2014 GDHS report, the participants of this survey were sampled using a two-stage sampling technique. The sampling process started with the random selection of 427 clusters (hereinafter community) that were representative both at the national (10 regions) and residence (urban and rural) level using the 2010 Ghana population and housing census sampling frame as a guide. Furthermore, using systematic sampling technique about 30 houses were chosen from each cluster amounting to 12,831. Among the selected houses, 12, 010 were occupied and the remaining houses were vacant. A response rate of $99 \%$ was achieved for successfully interviewing 11,835housholds out of the 12,010 households. Overall, 9396 women aged 15-49 years were interviewed after consenting to participate out of the 9656 women that were eligible for the survey in the interviewed households representing $97 \%$ response rate [7]. This nationwide survey captured information including women's reproductive health, health-seeking behavior, socioeconomic, and demographic background as well as geo-reference data. The Global Positioning System (GPS) data were collected for all the 427 communities in Ghana. Out of the 9396 interviewed women, a subgroup of 4292 respondents gave birth in the previous 5 years before the survey and were asked whether they received skilled care 41 days after live delivery (Fig. 2). All the eligible participants (4292) responded to the interview question, which constituted the study sample for this research. More detailed information on the sampling procedure and data is published in the Ghana Demographic and Health Survey of 2014 [7].

\section{Study variables}

The dependent variable was whether the mother received PNC services from a skilled health care provider immediately or within 41 days after delivery. The outcome measure was coded 'yes or no' depending on the response to the questionnaire. The questions in the survey regarding PNC services were restricted to last delivery in the past five years hitherto the 2014 GDHS to 
limit recall bias. The coding structure for the outcome variable has been detailed in Table 1 .

The community-level and individual-level factors employed in this study were chosen using the Andersen health utilization model as displayed in Fig. 3. Community-level factors describe the characteristics of the community while the individual-level factors focus on women's attributes. Andersen's behavioral model highlights the health system and community characteristics as well as predisposing and enabling factors as facilitating and inhibitory factors for health care utilization [31, 32].

According to the 2014 GDHS, information about the usual community the women lived in, whether rural or urban was captured and was termed as area of residence in this study. Also, the 2014 GDHS collected information about whether women had an issue with distance to a health facility when seeking medical attention. This survey question captured self-reported information on women's perceived distance to a health facility in their community and was referred hereinafter in this study as community-level problem with distance to a health facility. According to the 2014 GDHS's original data file, the variable "problem with distance to facility" was a dummy variable, which was, had two responses either: 'a big problem' (indicating longer perceived distance) or 'not a big problem' (suggesting shorter perceived distance). This variable was used as a proxy to measure the association of community-level problem with distance to a health facility with the dependent variable as was done in an analogous study in Nigeria [25,33].

On the other hand, the community poverty level was categorized into two groups as reported in a similar study [34]. The community poverty level variable was created from the wealth index in the survey data. The GDHS wealth index was made from information on possession of household assets and dwelling factors including means of transport, refrigerator, toilet facilities among others [24]. The survey employed Principal component analysis to create wealth index [24] that was categorized into quintiles: poorest, poorer, middle, richer and richest. In this study, the poorest and poorer groups were merged to represent the poor category. The percentage of women who were poor per community was estimated. Community's level of poverty was coded as high ' 1 ' when above $50 \%$ otherwise was coded low ' 0 ' (Table 1).

The community level of education was generated from women's responses to the question "highest education attended" in the survey. The survey data categorized the highest education attended into 4 groups namely no education, primary (1-6 years), Secondary ( $7-12$ years) and higher. For this study, the higher education attended variable was created by combining secondary and higher education. The percentage of women with at least secondary education was computed for each community. Also, the community unemployment level was generated from the responses of women on either they were working or not. The survey data created two dummy variables of employment: working ' 1 ' and not working ' 0 '. The percentage of unemployment per community was calculated. The study variables such as community level of education $(p$-value $=0.67)$ and community unemployment level $(p$-value $=0.29)$ did not fail the linearity test and were examined as a continuous variable. The community-level factors that were analyzed to explain the discrepancies in the utilization of PNC services include the area of residence, community-level problem with distance to a health facility, community poverty level, community education level, and community unemployment level.

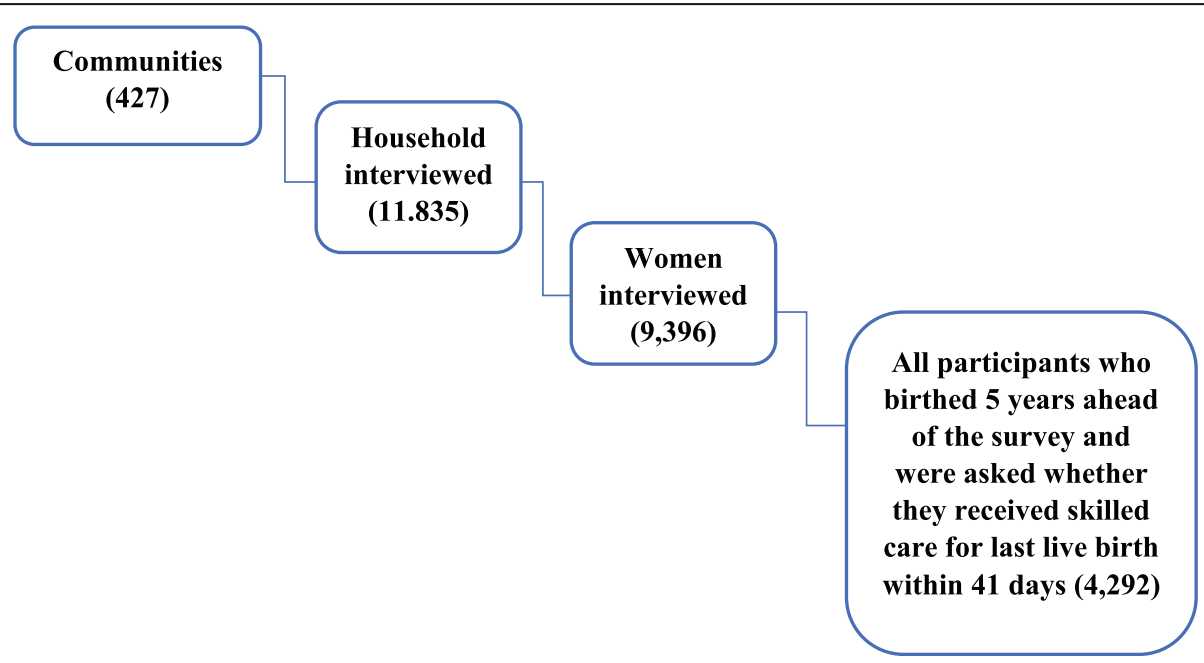

Fig. 2 Hierarchical structure of the 2014 GDHS data 
Table 1 Summary of study variables

\begin{tabular}{|c|c|c|}
\hline Variable name & Variable Description & Coding structure \\
\hline \multicolumn{3}{|l|}{ Dependent variable } \\
\hline Postnatal care usage & $\begin{array}{l}\text { Whether postnatal care was received within } 41 \text { days } \\
\text { after live birth or not }\end{array}$ & Categorized, $0=$ No, $1=$ Yes \\
\hline \multicolumn{3}{|l|}{ Individual-level variables } \\
\hline Maternal age & Maternal age in years & Continuous, ranged from 15 to 49 years \\
\hline Marital status & Current marital status & $\begin{array}{l}\text { Categorized, } 1=\text { Single, } 2=\text { Cohabitating, } \\
3=\text { Widow/divorced/separated, } \\
4=\text { Married }\end{array}$ \\
\hline Religion & Women's religious affiliation & $\begin{array}{l}\text { Categorized, } 1=\text { Traditional/other, } 2=\text { Muslim, } 3= \\
\text { Christian }\end{array}$ \\
\hline Ethnicity & Ethnic group of the women & $\begin{array}{l}\text { Categorized, } 1=\text { Akan, } 2=\text { Northern tribes, } 3=\text { Ewe, } 4= \\
\text { Ga, } 5=\text { Other }\end{array}$ \\
\hline Parity & History of births & $\begin{array}{l}\text { Categorized, } 1=\text { One birth, } 2=\text { Two births, } 3=\text { Three or } \\
\text { more births }\end{array}$ \\
\hline Educational attainment & Highest educational level & $\begin{array}{l}\text { Categorized, } 0=\text { No Education, } 1=\text { Primary, } 2= \\
\text { Secondary } / \text { Higher }\end{array}$ \\
\hline Wealth status & Wealth status of household & Categorized, $1=$ Poor, $2=$ Middle, $3=$ Rich \\
\hline Employment status & Working status of the women & Categorized, $1=$ Not Working, $2=$ Working \\
\hline \multicolumn{3}{|l|}{ Community-level variables } \\
\hline $\begin{array}{l}\text { Community problem with } \\
\text { distance to health facility }\end{array}$ & $\begin{array}{l}\text { Perceived problem with distance to a health facility } \\
\text { when seeking medical care }\end{array}$ & $\begin{array}{l}\text { Categorized, } 0=\text { not a big problem (short distance), } 1= \\
\text { big problem (long distance) }\end{array}$ \\
\hline Area of residence & Whether community is rural or urban & Categorized, $0=$ Rural, $1=$ Urban \\
\hline Community poverty level & $\begin{array}{l}\text { Percentage of women who were poor based on } \\
\text { wealth status per community }\end{array}$ & Categorized, $0=$ Low $(\leq 50 \%), 1=$ High (>50\%) \\
\hline Community educational level & $\begin{array}{l}\text { Percentage of women with at least secondary } \\
\text { education per community }\end{array}$ & Continuous, ranged from 0 to 100 \\
\hline Community unemployment level & Percentage of women without work per community & Continuous, ranged from 0 to 81.3 \\
\hline
\end{tabular}

Individual-level variables that were studied in this research were maternal age, marital status, religion, ethnicity, parity, education, wealth status, and employment status. As exhibited in Table 1 of this study, maternal age was examined as a continuous variable. Marital status was grouped as single, cohabitating, widow/divorced/ separated and married. In terms of religion, this study classified women into traditionalist or other, Muslim, and Christian. Also, ethnicity was classified as Akan, Northern tribes, Ewe, Ga, and other groupings. For this research, the parity of the women was grouped into 1 birth, 2 births, and $\leq 3$ births. Women's highest education level was classified into no education, primary, secondary or higher. This study grouped women's wealth status into poor, middle, and rich classifications. Finally, women's employment status was grouped into not working and working. The categorizations of the study predictors were adopted from the literature $[35,36]$.

\section{Descriptive statistics}

This research employed Chi-square tests to ascertain the differences in the distribution of women across all the categories of the explanatory variables. In this study, proportions and frequencies of postnatal care services use were tabulated according to the hypothesized sociodemographic and economic predictors for women of child-bearing age. Mean, standard deviation, median and interquartile range (IQR) were used for quantitative variables.

\section{Spatial clustering}

This study hypothesized that spatial autocorrelations exist in the use of PNC services across communities. Kulldorff's spatial scan statistics is a powerful tool to detect spatial autocorrelations based on geographic positioning [37]. This technique was employed in this study to identify local clusters of PNC services across the communities. For analyses, this study used the GDHS spatial data that only allows a set of coordinates per community. A purely spatial analysis was conducted using a discrete binomial model to scan for communities with high rates of non-utilization of PNC services in Ghana. SaTScan technique used in this study hypothesized that the risk of non-use of PNC services was likely different between the inner and outer parts of a circular window. The circular- shape spatial window scan communities to 


\section{Community and health system factors}

Poverty level

\section{Unemployment level}

Area of residence

\section{Women with at least High school}

Distance to a health facility

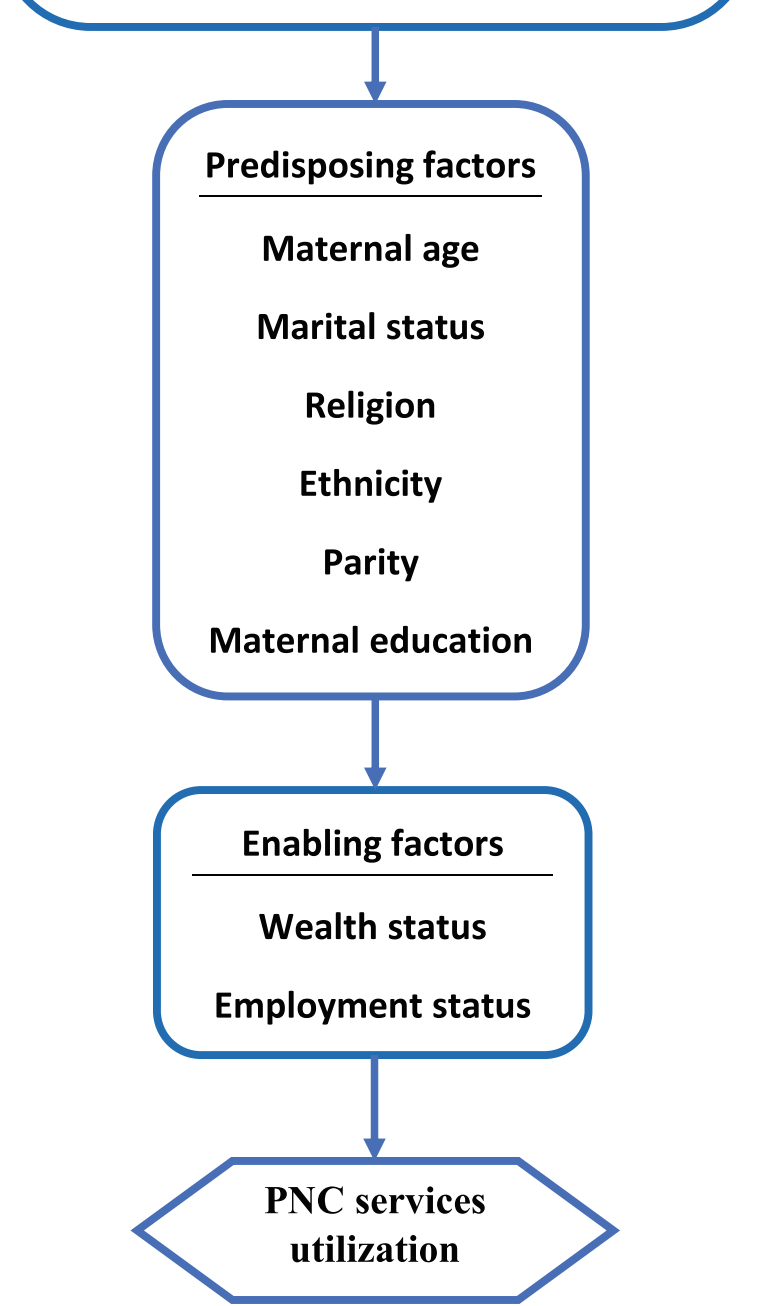

Fig. 3 Adapted Andersen's health utilization model for PNC services utilization

identify areas with a maximum spatial cluster size of $50 \%$ of the population at risk. The probability model relied on Monte Carlo simulation with replication of 999 and $50 \%$ of the population at risk was considered the maximum size of a spatial cluster [38]. The analyses were conducted using SaTScan software, version 9.6.0. The outputs generated from SaTScan analyses were displayed on Google Map to highlight the spatial patterns of non-use of PNC services.

\section{Inferential statistics}

\section{Multilevel mixed regression model}

Given the sampling technique and the hierarchical nature of the weighted 2014 GDHS data, a 2-level mixed logistic regression model was specified for the dichotomous outcome [20, 39] using mean-variance adaptive Gauss-Hermite quadrature at an integration point of 12 . The components of the model were level one (individuals) nested in level two (communities). This study considers the error in the second level as a random effect to check for disparities in the likelihood of PNC services usage across the communities. The two-level mixed model used is stated below.

Equation 1: Multilevel mixed logistic regression model where $\mu \mathrm{j} \sim \mathrm{N}\left(0, \sigma^{2}\right.$ group $) ; \beta_{0}$, intercept; $\beta_{\mathrm{k}}$, regression coefficient of the variables; $\mathrm{X}_{\mathrm{ki}}$, study predictors; $\sigma^{2}$ group, community-level variance. $p(Y i=1)=p i \operatorname{Logit}(\mathrm{pi})=\beta_{0}$ $+\beta_{1} \mathrm{X}_{1}+\beta_{2} \mathrm{X}_{2} \ldots+\beta_{\mathrm{k}} \mathrm{X}_{\mathrm{ki}}+\mu_{\text {group }(\mathrm{i})}$

Three models were estimated in this study. A null model was first fitted with no covariates. Second, unconditional mixed logistic regression analyses were conducted between the use of PNC services and each individual-level as well as community-level predictors. Unadjusted odds ratios were generated and correlations with liberal $p$-values of 0.25 or less were selected as candidates for the multivariate 2-level mixed modeling [40]. This unconventional cut-off was used to avoid the elimination of important predictors that could be masked or suppressed by other control variables [40, 41]. Lastly, as proposed by Hosmer and Lemeshow [41], a selection method that manually eliminates insignificant factors was utilized in the final model. This backward technique sequentially removes less relevant characteristics, beginning with the highest $\mathrm{p}$-value and eventually retaining just significant predictors with a p-value less than or equal to 0.05 .

A complete case analysis was used in this study to remove subjects with missing values. A polynomial model was used to test the assumption of linearity for age by introducing a quadratic term. Multicollinearity test for selected individual-level predictors was done to ensure inflated standard errors due to many predictors measuring the same characteristics are controlled. In this research, the parameters for variance inflation factor (VIF) $\leq 2.5$ and tolerance $\geq 0.4$ were set as recommended by Johnston et al. [42] for the logistic regression model to identify potentially redundant variables due to collinearity. 
Type-3 likelihood ratio test was used to examine categorical explanatory variables that have classifications greater than two. Predictors were considered confounders if the difference in the regression coefficient in the unconditional and conditional model was $>20 \%$ [40]. This study tested interactions among predictors that were significant in the multivariable model.

The final model had both fixed and random effects, which were reported as odds ratios and intraclass correlation coefficients (ICC) respectively. To compare the effect on individuals across the communities, this study manually calculated population-averaged odds ratios (ORs) and 95\% confidence intervals from the subjectspecific coefficients from the final model using the following equation:

Equation 2 Population-averaged Odds Ratios

$$
\beta_{\mathrm{PA}}=\beta /\left(\sqrt{ }\left(1+0.346 \sigma^{2} \text { group }\right)\right)
$$

where $\sigma_{\text {group }}^{2}$ is community-level variance, $\beta$ is the subject-specific regression coefficient.

Based on the latent response variable approach [43], the variance partition coefficient (VPC) which is also referred to as Intraclass Correlation Coefficient (ICC) was calculated for the community in both the null and final model, which measures the variability in the dependent variable attributable to the contextual level [44]. The VPC was computed from this formula below.

Equation 3: Variance Partition Coefficient (VPC)

$$
\begin{aligned}
& \mathrm{VPC}=\sigma^{2} \text { group } /\left(\left(\sigma^{2} \text { group }+\pi^{2} / 3\right) . \text { where } \sigma_{\text {group }}^{2}\right. \text { is community } \\
& \text { - level variance. }
\end{aligned}
$$

This study computed "design effect (deff)", the quotient of the variance in a clustered data structure relative to that in an independent structure. Due to the fact that the variation within or between clusters for discrete data is not always constant, deff is an approximation [45].

Equation 4: Design effect, deff $\approx 1+(C-1) \times$ ICC, where $\mathrm{C}$ is average cluster size and ICC represents intraclass correlation coefficient.

The final model in this study was compared with the null model, and a smaller value of Akaike's Information Criterion (AIC) and Bayesian Information Criterion (BIC) was regarded as a parsimonious model [46]. Also, model diagnostics was done using the area under the curve (AUC) of the receiver-operating characteristic (ROC). Alpha level of 0.05 was used to gauge the association that was statistically significant in this current research. STATA 14 (Stata Corp. Inc., TX, USA) was employed in this study.

\section{Results}

\section{Descriptive statistics}

In this study, a total of 427 communities were examined and within all these communities $84 \%$ of the women who reported having given live birth within the past 5 years, utilized PNC services whilst 16\% did not use with significant inequities in the utilization of this essential service (Fig. 4).

\section{Spatial autocorrelation}

The median number of study participants per community that reported non-use of PNC services was 1 (IQR: 0-2). Regarding clusters with high rates of nonutilization of PNC services, this study found significant spatial autocorrelations of non-use of PNC services in Ghana (Fig. 5). The spatial scan statistic output identified 4 significant clusters with disproportionately higher non-usage of PNC services than their neighboring communities. The biggest cluster composed of 13 communities in the northern region and three communities in the Volta region, covering a diameter of $123.9 \mathrm{~km}$. This cluster had a relative risk of 3.97 ( $p$-value $<0.00001$ ) which indicates that study participants who dwell in the area were 3.97 times more likely to miss PNC services than surrounding communities. Also, a second cluster was detected among ten northern communities covering a diameter of $80.1 \mathrm{~km}$. The risk of not receiving PNC services among respondents who resided in this cluster area was 3.93 times more when compared to those outside that locality. Furthermore, this study detected another significant cluster that comprised of 15 communities: Volta region (8 communities), Brong Ahafo (2 communities) and Northern region (5 communities). The cluster diameter was $78.8 \mathrm{~km}$ and the relative risk of not using PNC services in the clustered area was 2.36 (pvalue $<0.000003$ ). This revealed that study participants who live in this locality were 2.36 times more likely not to utilize PNC services relative to bordering communities (Fig. 5). Lastly, a cluster was identified in the Eastern region of Ghana which was made up of five communities covering a diameter of $40.78 \mathrm{~km}$; the odds of not using PNC services in this clustered locality had a was 3.51 times higher than respondents in the surrounding communities (Fig. 5).

\section{Community-level characteristics}

The distribution of study predictors by the community has been outlined in Table 2. Concerning the community-level problem with distance to a health facility, $69.3 \%$ of the communities did not have a big problem with distance to a health facility while $30.7 \%$ had a big problem with distance to a health facility. In terms of PNC services utilization, 87.5 and $76.0 \%$ utilization rates were found in communities that did not have a big 


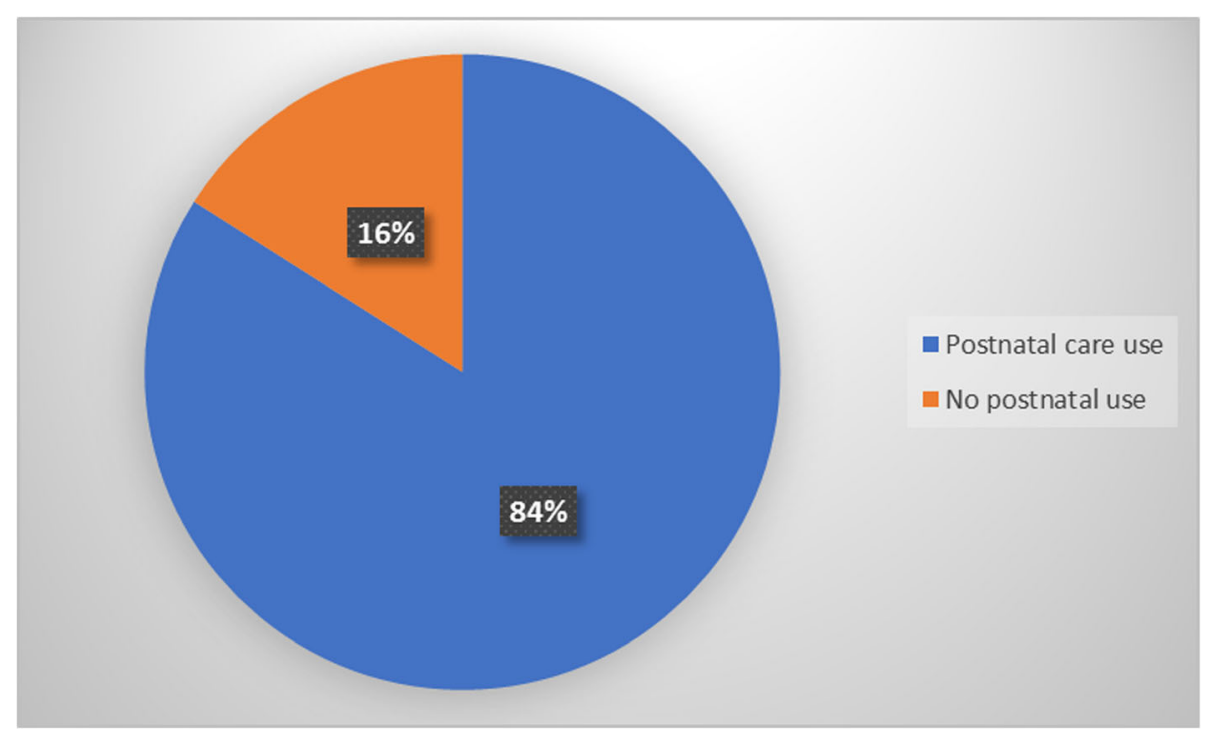

Fig. 4 Distribution of postnatal care service utilization among reproductive aged Ghanaian women, 2014 GDHS data

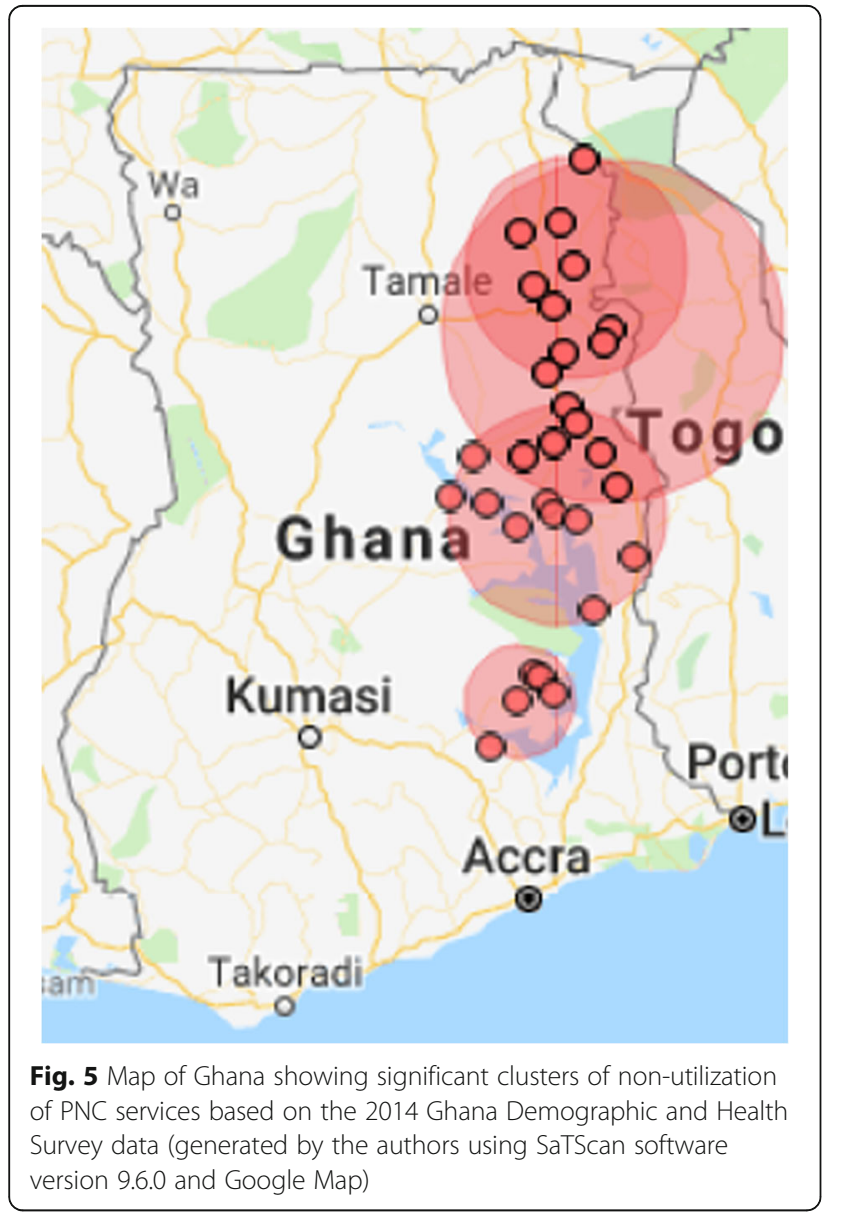

problem with distance to a health facility and communities with a big problem with distance to a health facility respectively.

Regarding area of residence, about $58.6 \%$ of the communities were in rural areas whereas about two-fifth $(41.6 \%)$ of the communities were situated in the urban areas. The utilization rate of PNC services in urban communities was $98.0 \%$ whilst $78.4 \%$ occurred in rural communities (Table 2).

With respect to poverty levels of communities, PNC services utilization rate was $71 \%$ in communities with a high poverty level whereas it was $89.3 \%$ in communities with a low poverty level (Table 2). This implies that respondents residing in poorer communities have lower utilization of PNC services. The average communitylevel percentage of respondents with at least secondary education was $45.1 \pm 26.02$. Community unemployment level variable met the linearity assumption ( $p$-value $=$ 0.29 ). The average percentage of communities' unemployment was $26.4 \pm 13.01$ (Table 2).

\section{Individual-level characteristics}

Table 2 displays the distribution of individual-level socioeconomic control variables by PNC services use. Regarding age, the linearity assumption was not violated ( $\mathrm{p}$-value $=0.148)$ and hence was analyzed as a continuous variable. Overall, 4292 study participants were included in the study, their ages were from 15 to 49 years with a mean age of $30.9 \pm 7.3$ years. Among respondents who received PNC services, the average age was $30.6 \pm$ 7.0 year (Table 2 ).

Regarding marital status, $65.2 \%$ of the study participants were married, $19.3 \%$ were cohabitating, $8.5 \%$ were 
Table 2 Distribution of women by predictors and PNC services utilization, and unadjusted odds ratios (UOR), 95\%Cl, and p-values for predictors of using PNC services among Ghanaian women from the univariable 2-level logistic regression model

\begin{tabular}{|c|c|c|c|}
\hline Predictors & $\begin{array}{l}\text { Overall }(N= \\
4292) \%\end{array}$ & $\begin{array}{l}\text { Used postnatal care }(N= \\
3605) \%\end{array}$ & $\begin{array}{l}\text { No postnatal care }(N= \\
687) \%\end{array}$ \\
\hline Individual-level characteristics & $\mathrm{N}(\%)$ & $\mathrm{N}(\%)$ & $\mathrm{N}(\%)$ \\
\hline Age (Mean $\pm S D$ ) & $30.9 \pm 7.33$ & $30.6 \pm 7.03$ & $31.3 \pm 7.62$ \\
\hline \multicolumn{4}{|l|}{ Marital status } \\
\hline Single & $363(8.5)$ & $317(87.3)$ & $46(12.7)$ \\
\hline Cohabitating & $830(19.3)$ & $672(81.0)$ & $158(19.0)$ \\
\hline Widow/divorced/separated & $300(7.0)$ & $254(84.7)$ & $46(15.3)$ \\
\hline Married & $2799(65.2)$ & $2362(84.4)$ & $437(15.6)$ \\
\hline \multicolumn{4}{|l|}{ Religion } \\
\hline Traditional/other & $324(7.5)$ & $183(56.5)$ & $141(43.5)$ \\
\hline Islam & $922(21.5)$ & $801(86.9)$ & $121(13.1)$ \\
\hline Christians & $3046(71.0)$ & $2621(86.0)$ & $425(14.0)$ \\
\hline \multicolumn{4}{|l|}{ Ethnicity $^{b}$} \\
\hline Akan & $1642(38.3)$ & $1473(89.7)$ & $169(10.3)$ \\
\hline Northern tribes & $1795(41.8)$ & $1411(78.6)$ & $384(21.4)$ \\
\hline Ewe & $476(11.1)$ & $391(82.1)$ & $85(17.9)$ \\
\hline $\mathrm{Ga}$ & $198(4.6)$ & $179(90.4)$ & $19(9.6)$ \\
\hline Other & $180(4.2)$ & $150(83.3)$ & $30(16.7)$ \\
\hline \multicolumn{4}{|l|}{ Parity } \\
\hline One birth & $935(21.8)$ & $826(88.3)$ & $109(11.7)$ \\
\hline Two births & $838(19.5)$ & $737(88.0)$ & $101(12.1)$ \\
\hline Three or more births & $2519(58.7)$ & $2042(81.1)$ & $477(18.9)$ \\
\hline \multicolumn{4}{|l|}{ Educational attainment } \\
\hline No education & $1418(33.0)$ & $1051(74.1)$ & $367(25.9)$ \\
\hline Primary & $869(20.3)$ & $725(83.4)$ & $144(16.6)$ \\
\hline Secondary/Higher & $2005(46.7)$ & $1829(91.2)$ & $176(8.8)$ \\
\hline \multicolumn{4}{|l|}{ Wealth status } \\
\hline Poor & $2241(52.2)$ & $1703(76.0)$ & $538(24.0)$ \\
\hline Middle & $811(18.9)$ & $751(89.0)$ & $89(11.0)$ \\
\hline Rich & $1240(28.9)$ & $1180(95.2)$ & $60(4.8)$ \\
\hline \multicolumn{4}{|l|}{ Employment status $^{\mathrm{a}}$} \\
\hline Not working & $886(20.7)$ & $760(85.8)$ & $126(14.2)$ \\
\hline Working & $3403(79.3)$ & $2842(83.5)$ & $561(16.5)$ \\
\hline \multicolumn{4}{|l|}{ Community-level characteristics } \\
\hline \multicolumn{4}{|c|}{ Community Problem with distance to health facility } \\
\hline Not a big problem & $2973(69.3)$ & $2603(87.5)$ & $370(12.5)$ \\
\hline Big problem & $1319(30.7)$ & $1002(76.0)$ & $317(24,0)$ \\
\hline \multicolumn{4}{|l|}{ Area of residence } \\
\hline Urban & $1777(41.4)$ & $1634(92.0)$ & $143(8.0)$ \\
\hline Rural & $2515(58.6)$ & $1971(78.4)$ & $544(21.6)$ \\
\hline \multicolumn{4}{|l|}{ Community Poverty level } \\
\hline Low & $3046(71.0)$ & $2720(89.3)$ & $326(10.7)$ \\
\hline High & $1246(29.0)$ & $885(71.0)$ & $361(29.0)$ \\
\hline
\end{tabular}


Table 2 Distribution of women by predictors and PNC services utilization, and unadjusted odds ratios (UOR), 95\%Cl, and $p$-values for predictors of using PNC services among Ghanaian women from the univariable 2-level logistic regression model (Continued)

\begin{tabular}{|c|c|c|c|}
\hline Predictors & $\begin{array}{l}\text { Overall }(N= \\
4292) \%\end{array}$ & $\begin{array}{l}\text { Used postnatal care }(N= \\
3605) \%\end{array}$ & $\begin{array}{l}\text { No postnatal care }(N= \\
687) \%\end{array}$ \\
\hline $\begin{array}{l}\text { Percentage of women with at least secondary education per } \\
\text { community (Mean } \pm \text { SD) }\end{array}$ & $45.1 \pm 26.02$ & $54.6 \pm 26.11$ & $35.6 \pm 26.20$ \\
\hline \multicolumn{4}{|l|}{ Community unemployment level } \\
\hline Percentage of women without work per community (Mean \pm SD) & $26.4 \pm 13.01$ & $27.6 \pm 12.95$ & $25.2 \pm 13.06$ \\
\hline
\end{tabular}

$\mathrm{N}$, number of observations; SD, standard deviation; \%, percent; ${ }^{a} \mathrm{~N}=4289$ and ${ }^{\mathrm{b}} \mathrm{N}=4291$, due to missing values; $\mathrm{Cl}$, confidence in; GDHS data 2014

single while $7.0 \%$ were divorced or widowed or separated. Comparison in the use of PNC services by marital status showed that $87.3 \%$ of single respondents received PNC services, $84.7 \%$ of divorced or widowed or separated, $84.4 \%$ of married and $81.0 \%$ of cohabitating study participants used PNC services (Table 2).

Concerning religion, Christians represented $71 \%$ of the study respondents. Muslims accounted for $21.5 \%$ of women whilst $7.5 \%$ were traditional or other believers. In connection with PNC services, $56.5 \%$ of women who were traditional or other believers used PNC services. Most Christians (86.0\%) and Muslims (86.9\%) received PNC services (Table 2).

Northern tribes constituted $41.8 \%$ of the study population followed by Akans (38.3\%) while other ethnic groupings were the least represented (4.2\%) among the study participants corresponding with their percentage in the population. The highest utilization of PNC services was found among Ga respondents (90.4\%) whereas northern tribe respondents had the highest nonutilization of PNC services (21.4\%)(Table 2).

Considering parity, $58.7 \%$ of study participants had at least 3 births whereas 21.8 and $19.5 \%$ of the them had given birth once and twice respectively. Further, 81.1\% of study participants who had given birth thrice or more used PNC services. Among study respondents who had one birth and two births, 88.3 and $88.0 \%$ respectively received PNC services (Table 2).

Concerning education, $33.0 \%$ of study participants had no education and $46.7 \%$ had at least secondary education. In terms of the use of PNC services, $83.4 \%$ of respondents who attained primary education and $91.2 \%$ of respondents who had secondary or higher education received PNC services. Among study participants with no education, 74.1\% used PNC services (Table 2).

As for wealth status, more than half $(52.2 \%)$ of the respondents were considered poor, $28.9 \%$ were rich, and the remaining $18.9 \%$ were middle-class. Regarding uptake of PNC services, $76 \%$ of poor respondents received PNC service whereas 81.4 and $95.2 \%$ of middle-class and rich respondents used PNC services respectively (Table 2). Referring to respondents' employment status, 79.3\% were working and $83.5 \%$ of those working received PNC services compared to $85.8 \%$ of study participants who were not working (Table 2).

\section{Inferential statistics}

Univariable analysis results: Two-level mixed models were fitted to account for community-level variance. Most communities had more than one respondent who participated in the 2014 GDHS, and this has the tendency to cause clustering in the dataset. The number of respondents in the community ranged from 1 to 33 with an average of about 10 study participants per community. The design effect of 4.3 computed in this study suggested a clustered data structure and hence justified the use of multilevel analysis as proposed by Maas and Hox [45]. In the univariate model, only women's marital ( $p$ value $=0.4)$ and employment $(\mathrm{p}$-value $=0.8)$ status had $p$-values greater than 0.25 and were excluded from the study (Table 3 ).

\section{Multivariable analysis results}

Apart from marital status and employment status variables that were not considered in the adjusted model, the rest of the study variables were tested for multicollinearity. All risk factors that were selected for the adjusted model had VIF $\leq 2.5$ and tolerance $\geq 0.4$. In addition, the overall mean VIF of 1.58 indicated that multicollinearity was not considered problematic (Table 4).

As shown in Table 5, the final model had smaller AIC and $\mathrm{BIC}$; therefore, was selected as a more parsimonious model $(\mathrm{AIC}=3146.7 ; \quad \mathrm{BIC}=3235.8)$ than the model without risk factors $(\mathrm{AIC}=3304.9, \mathrm{BIC}=3317.6)$. The AUC of 0.86 (95\%CI: $0.85-0.87)$ from the ROC curve demonstrates the model is a good binary classifier of PNC service use or not (Fig. 6).

The results from the multivariable 2-level mixed model with logit link function are shown in Table 5 . In this study, potential confounders were maintained in the model. No interaction term was found beyond the significant main effects of the predictors in the multivariable model. 
Table 3 Distribution of women by predictors and PNC services utilization, and unadjusted odds ratios (UOR), 95\%Cl, and p-values for predictors of using PNC services among Ghanaian women from the univariable 2-level mixed logistic regression model

\begin{tabular}{|c|c|c|}
\hline Predictors & UOR $(95 \% \mathrm{Cl})$ & P-value \\
\hline \multicolumn{3}{|l|}{ Individual-level characteristics } \\
\hline Age (years) & $0.98(0.97,0.99)$ & 0.02 \\
\hline \multicolumn{3}{|l|}{ Marital status } \\
\hline Cohabitating & $0.84(0.55,1.27)$ & 0.4 \\
\hline Widow/divorced/separated & $0.94(0.56,1.57)$ & \\
\hline Married & $1.05(0.72,1.53)$ & \\
\hline Single & Reference & \\
\hline \multicolumn{3}{|l|}{ Religion } \\
\hline Islam & $3.03(1.98,4.65)$ & $<0.0001$ \\
\hline Christians & $3.04(2.18,4.22)$ & \\
\hline Traditional/other & Reference & \\
\hline \multicolumn{3}{|l|}{ Ethnicity } \\
\hline Akan & $1.88(1.26,2.81)$ & 0.0001 \\
\hline Northern tribes & $1.07(0.71,1.62)$ & \\
\hline Ga & $2.69(1.35,5.33)$ & \\
\hline Other & $0.85(0.49,1.66)$ & \\
\hline Ewe & Reference & \\
\hline \multicolumn{3}{|l|}{ Parity } \\
\hline Three or more births & $0.65(0.50,0.85)$ & 0.0005 \\
\hline Two births & $0.96(0.69,1.33)$ & \\
\hline One birth & Reference & \\
\hline \multicolumn{3}{|l|}{ Educational attainment } \\
\hline No education & $0.41(0.31,0.52)$ & $<0.0001$ \\
\hline Primary & $0.52(0.40,0.69)$ & \\
\hline Secondary/Higher & Reference & \\
\hline \multicolumn{3}{|l|}{ Wealth status } \\
\hline Poor & $0.18(0.13,0.26)$ & $<0.0001$ \\
\hline Middle & $0.39(0.27,0.58)$ & \\
\hline Rich & Reference & \\
\hline \multicolumn{3}{|l|}{ Employment status } \\
\hline Working & $0.97(0.76,1.24)$ & 0.8 \\
\hline Not working & Reference & \\
\hline \multicolumn{3}{|c|}{ Community-level characteristics } \\
\hline \multicolumn{3}{|c|}{ Community Problem with distance to health facility } \\
\hline Not a big problem & $1.39(1.11,1.73)$ & 0.004 \\
\hline Big problem & Reference & \\
\hline \multicolumn{3}{|l|}{ Area of residence } \\
\hline Urban & $3.32(2.35,4.68)$ & $<0.0001$ \\
\hline Rural & Reference & \\
\hline \multicolumn{3}{|l|}{ Community Poverty level } \\
\hline High & $0.28(0.20,0.41)$ & $<0.0001$ \\
\hline Low & Reference & \\
\hline
\end{tabular}

Community Education level 
Table 3 Distribution of women by predictors and PNC services utilization, and unadjusted odds ratios (UOR), 95\%Cl, and p-values for predictors of using PNC services among Ghanaian women from the univariable 2-level mixed logistic regression model (Continued)

\begin{tabular}{lll}
\hline Predictors & UOR (95\% Cl) & P-value \\
\hline Percentage of women with at least secondary education per community & $1.03(1.02,1.04)$ & $<0.0001$ \\
Community unemployment level & $1.01(0.99,1.02)$ & 0.22 \\
\hline Percentage of women without employment per community &
\end{tabular}

\section{Community-level effect (random effects)}

In this study, intraclass correlation coefficients (ICC) computed from the 2-level mixed logistic regression models were used to measure the degree of heterogeneity in PNC services use accounted for by the differences between communities. The ICCs showed significant proportions of variability in PNC utilization in this study. The intercept only model (without study variables) examined in this study reported significant variation in PNC services utilization across the communities (ICC $=0.36$ (95\% CI: $0.30-0.42)$. The variation in the use of PNC services across the community continued to be significant after including individual-level study predictors. The result from the final model showed that 24\% (95\% CI: $0.18-0.30)$ of the unobserved variation in PNC services utilization could be explained by community heterogeneity (Table 5).

Moreover, the results of the association between community-level predictors and receiving PNC services are shown in Table 5. This analysis indicates that the odds of using PNC services by a woman, who resided in a community with a higher poverty level was 0.60 (95\%CI:0.44-0.81) times lower than a woman who lived in a community with a lower poverty level. Also, a moderate association between community-level secondary or higher education and the use of PNC services was identified. For a one percentage change in the level of community secondary or higher education, the odds of using PNC services increases by 1.01 (95\%CI:1.01-1.02) times. However, the analyses indicate that the effect of a community-level problem with distance to a health facility, area of residence and community-level unemployment on the utilization of PNC services in the crude model were diminished in the multivariable model after controlling for other explanatory factors. The use of PNC services did not have an independently significant association with community problem with distance to a health facility ( $\mathrm{AOR}=1.08,95 \% \mathrm{CI}: 0.89,1.32$ ), area of residence $\quad(\mathrm{AOR}=1.05, \quad 95 \% \mathrm{CI}: \quad 0.75-1.46) \quad$ and community-level unemployment $(\mathrm{AOR}=0.99,95 \% \mathrm{CI}$ : 0.98-1.00).

\section{Individual-level effect}

Based on Table 5, the findings of this study show that religion, ethnicity, education, and wealth status emerged as significantly associated with services uptake. The study results showed that Muslims $(\mathrm{AOR}=2.42,95 \% \mathrm{CI}$ : 1.68-3.49) and Christians (AOR $=1.99$, 95\%CI: $1.50-$ 2.63) were more likely to receive PNC services compared

Table 4 Results of multicollinearity test for selected predictors for the multivariable model

\begin{tabular}{lll}
\hline Predictors & VIF & Tolerance \\
\hline Individual-level characteristics & 1.66 & 0.60 \\
Age & 1.21 & 0.83 \\
Religion & 1.03 & 0.97 \\
Ethnicity & 1.73 & 0.58 \\
Parity & 1.86 & 0.54 \\
Education & 2.42 & 0.41 \\
Wealth status & & 0.75 \\
Community-level characteristics & 1.33 & 0.55 \\
Community Problem with distance to health facility & 1.82 & 0.40 \\
Area of residence & 2.50 & 0.66 \\
Community Education level & 1.52 & 0.95 \\
Community Poverty level & 1.05 & $\mathbf{1 . 5 8}$ \\
Mean VIF & & \\
\hline
\end{tabular}


Table 5 Population-averaged Odds ratios (OR) and 95\% Cl for socioeconomic predictors of using PNC services among Ghanaian women from the final 2-level mixed logistic regression model

\begin{tabular}{|c|c|c|c|}
\hline Predictors & $\begin{array}{l}\text { Null model } \\
\text { OR }(95 \% \mathrm{Cl})\end{array}$ & $\begin{array}{l}\text { Final model } \\
\text { AOR }(95 \% \mathrm{Cl})\end{array}$ & P-value \\
\hline \multicolumn{4}{|l|}{ Fixed effect } \\
\hline \multicolumn{4}{|l|}{ Individual-level characteristics } \\
\hline Age (years) & & $1.00(0.98,1.01)$ & 0.9 \\
\hline \multicolumn{4}{|l|}{ Religion } \\
\hline Muslim & & $2.42(1.68,3.49)^{*}$ & $<0.000$ \\
\hline Christians & & $1.99(1.50,2.63)^{*}$ & $<0.000$ \\
\hline Traditional/other & & Reference & \\
\hline \multicolumn{4}{|l|}{ Ethnicity } \\
\hline Akan & & $1.46(1.05,2.05)^{*}$ & 0.03 \\
\hline Northern tribes & & $1.74(1.19,2.54)^{*}$ & 0.004 \\
\hline Ga & & $1.87(1.05,3.33)^{*}$ & 0.03 \\
\hline Other & & $1.05(0.62,1.77)$ & 0.9 \\
\hline Ewe & & Reference & \\
\hline \multicolumn{4}{|l|}{ Educational attainment } \\
\hline No education & & $0.72(0.56,0.92)^{*}$ & 0.009 \\
\hline Primary & & $0.60(0.61,0.99)^{*}$ & 0.04 \\
\hline Secondary/Higher & & Reference & \\
\hline \multicolumn{4}{|l|}{ Parity } \\
\hline Three or more births & & $0.87(0.69,1.11)$ & 0.3 \\
\hline Two births & & $1.01(0.76,1.35)$ & 0.9 \\
\hline One birth & & Reference & \\
\hline \multicolumn{4}{|l|}{ Wealth status } \\
\hline Poor & & $0.44(0.31,0.63)^{*}$ & $<0.000$ \\
\hline Middle & & $0.60(0.43,0.85)^{*}$ & 0.004 \\
\hline Rich & & Reference & \\
\hline \multicolumn{4}{|l|}{ Community-level characteristics } \\
\hline \multicolumn{4}{|l|}{ Community Problem with distance to health facility } \\
\hline Not a big problem & & $1.08(0.89,1.32)$ & 0.4 \\
\hline Big problem & & Reference & \\
\hline \multicolumn{4}{|l|}{ Area of residence } \\
\hline Urban & & $1.05(0.75,1.46)$ & 0.8 \\
\hline Rural & & Reference & \\
\hline \multicolumn{4}{|l|}{ Community Poverty level } \\
\hline High & & $0.60(0.44,0.81)^{*}$ & 0.001 \\
\hline Low & & Reference & \\
\hline \multicolumn{4}{|l|}{ Community Education level } \\
\hline Percentage of women with at least secondary education per community & & $1.01(1.01,1.02)^{*}$ & 0.001 \\
\hline \multicolumn{4}{|l|}{ Community unemployment level } \\
\hline Percentage of women without employment per community & & $0.99(0.98,1.00)$ & 0.5 \\
\hline Random effects & Null model & Final model & \\
\hline Community level variance $(95 \% \mathrm{Cl}))$ & $1.84^{* *}(1.40,2.42)$ & $1.02(0.73,1.42)^{*}$ & \\
\hline ICC (95\% Cl) & $0.36(0.30,0.42)$ & $0.24(0.18,0.30)^{*}$ & \\
\hline
\end{tabular}

Model fit statistics 
Table 5 Population-averaged Odds ratios (OR) and 95\% Cl for socioeconomic predictors of using PNC services among Ghanaian women from the final 2-level mixed logistic regression model (Continued)

\begin{tabular}{lll}
\hline Predictors & Null model & Final model \\
AOR (95\% Cl)
\end{tabular}

Cl confidence interval, OR Odds ratio, SE Standard error, ICC Intraclass Correlation Coefficient, AIC Akaike Information Criterion, BIC Bayesian Information Criterion; ${ }^{*}$ significant at $p<0.05 ; \mathrm{GDHS}$ data 2014

to women who were traditional and other believers from any community. Similarly, odds of receiving PNC services by women who were Akan $(A O R=1.46$, 95\% CI: 1.05-2.05), Northern tribes $(\mathrm{AOR}=1.74$, 95\%CI: 1.19-2.54), and Ga (AOR $=1.87,95 \% \mathrm{CI}: 1.05-$ 3.33) were higher than Ewe women from any community. Also, the findings from this research highlighted that the odds of receiving PNC services among women with no education (AOR $=0.72$, 95\%CI: $0.56-$ $0.92)$ and primary educated women $(\mathrm{AOR}=0.60$, 95\%CI: 0.61-0.99) were lower when compared to women who attained secondary or higher education from any community. On wealth status, the odds of receiving $\mathrm{PNC}$ services among poor and middle-class women were $0.44(95 \% \mathrm{CI}: 0.31-0.63)$ and 0.60 (95\% CI: 0.43-0.85) times respectively lower than rich women who reside in any community. Conversely, individual-level factors such as age, and parity were not significantly associated with the use of PNC services (Table 5).

\section{Discussion}

This study reported a higher utilization rate of PNC services across communities than findings of the Sakeah study team in Ghana; this discrepancy may have arisen because they studied only two rural districts with a smaller sample size [12].

Also, this research found that the community-level variables: problems with distance to a health facility; area of residence; and community-level unemployment were not significantly associated with the use of PNC services. In agreement with this research, Mohan et al. [23] reported no significant association between communitylevel distance to a health facility and PNC services utilization. Also similar to this study, some researchers reported that the association between use of PNC services and area of residence was not significant [25, 33]. In addition, a study by Darega et al. [47] found no significant association between employment status and the use of PNC services. However, the results of this study are not consistent with other studies conducted in other

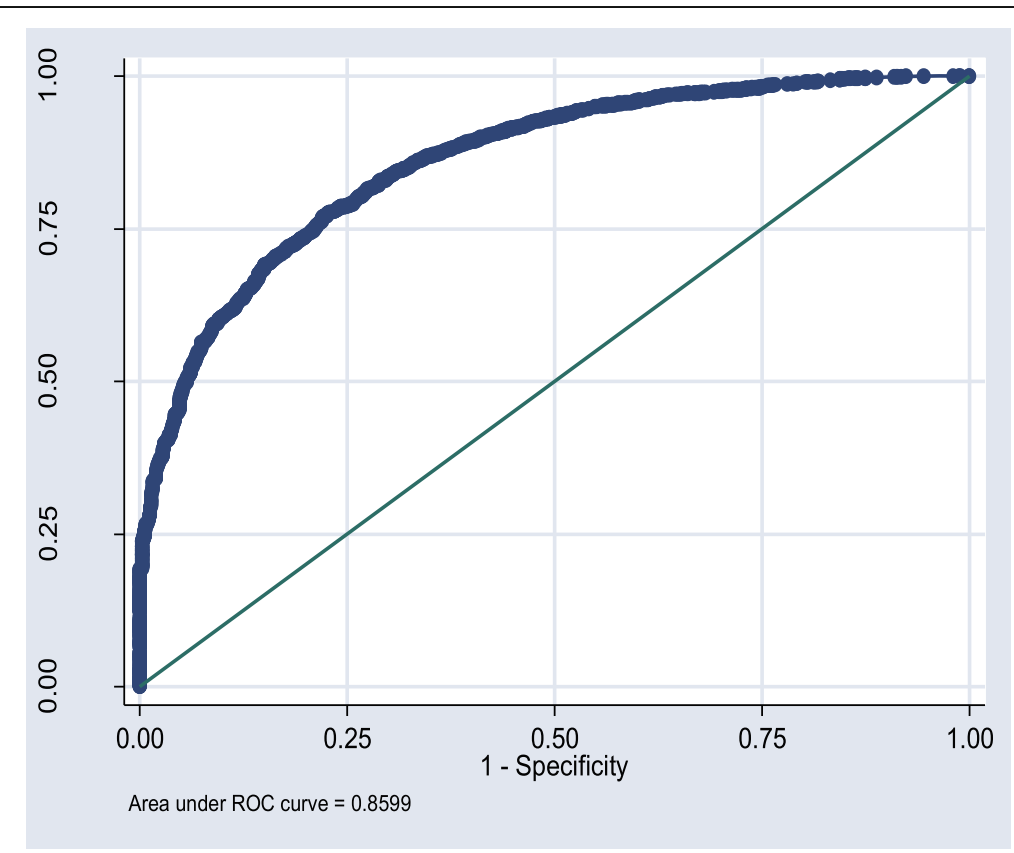

Fig. 6 Receiver Operating Characteristics curve of the final model 
developing countries which found a significant association between the use of PNC services and employment status [13]. This might be explained by the fact that contrary to these previous studies, which were carried out at the individual level, this study assessed community-level unemployment independent of individual level characteristics so there is a difference in the level of analysis.

Most importantly, this study found significant variability in use of PNC services utilization at the community level independent of individual-level characteristics. The association between community-level poverty and use of obstetric care services has long been established in the literature [34, 47-49]. Nonetheless, the evidence is somewhat mixed as the results from a previous study that was conducted in the rural part of Tanzania found no substantial association between community-level poverty and utilization of PNC services [23]. This current study adds to the body of evidence indicating that poverty at the community level matters over and above poverty at the individual level; this finding may be explained by women in poorer communities inability to afford indirect costs such as transportation, illegal fees being demanded at health facilities among other costs that are often required for accessing obstetric services [50], even though postdelivery care itself is free. Also, women from poorer communities might suffer discrimination from health workers $[51,52]$, which could make them avoid further contact with the health system including PNC services. Lastly, as expected evidence confirms that women from richer communities face lower barriers to receiving needed maternal healthcare [53].

Contrary to a study that found no significant effect of community-level education on the utilization of PNC services [23, 49], this research identified a significant association between the use of postnatal services and community-level education. The limited number of explanatory variables that were used in the previous studies could explain the discrepancies in the findings because confounding variables can potentially alter the results when they are insufficiently controlled. The findings of this study highlight the importance of community-level education, in that higher education could mean better access to health information and hence better understanding of the benefits of maternity services, and often more autonomy to choose evidencebased obstetric services rather than some potentially harmful cultural practices [54].

Additionally, this study identified that most of the significant clusters of non-utilization of PNC services were found in the Northern region. This result affirms the long-held notion of spatial disparities in the utilization of obstetric care services between northern and southern regions of Ghana $[48,55]$. Similar trends have been observed by other studies on maternal health services utilization [51, 52]. Also, this study revealed that a significant portion of the variation in PNC services use was attributed to unobserved community-level variance like other studies elsewhere [23, 49]. Specifically, this study found that about $24 \%$ of variability in the usage of PNC services could be explained by unmeasured communitylevel characteristics.

Apart from women's community poverty and educational level that may partially explain the inequalities in the use of PNC services as identified in this study, this spatial and unexplained variation in the utilization of PNC could be as a result of some potentially relevant community-level factors for which data are not available. The geographical variation in the non-utilization PNC services may be attributed to inadequate number of health facilities and health professionals in the northern region as suggested the earlier Addai study [55]. Also, media exposure tends to influence the community's uptake of maternal health services including PNC services based on previous studies [24, 34]. The differential usage of PNC services perhaps may be due to the influential role of cultural values and practices as reported in other studies [56]. However, the GDHS data lacks variables which could be used as proxies for cultural variables that influence maternal health-seeking behavior, and so further studies are required to unravel the influence of community's cultural underpinnings on the use of PNC services. Future research is warranted to identify further community-level characteristics that could explain the unmeasured community heterogeneity in PNC services uptake in Ghana. Notwithstanding, the link between the community where women reside, and the use of PNC services established in this study is of importance since it provides insight into the community-level influence to help address the inequalities in PNC services use.

Concerning individual-level predictors, some past studies did not find significant association between PNC services utilization and women's age $[23,49]$, marital status [25], employment status [14, 15], and parity [23] similar to the findings of this present study. In this current research, wealth status of women was found to be significantly associated with the use of PNC services. The odds of receiving PNC services were lower among the poor and middle-class women than rich women. This result is consistent with findings of studies conducted in Nigeria [20], India [28] and Bangladesh [57]. The literature seems to unequivocally suggest that wealthier women have better access to maternal health services in general since they can afford the ancillary costs that are related to accessing PNC services [58].

Also, some comparable studies in other developing countries reported that maternal education significantly influences PNC service utilization [20, 23, 59]. Consistent with these studies, this research found that lower 
education was negatively associated with uptake of PNC services. Specifically, this study identified lower odds of using of PNC services among women with no education and women with primary education relative to women with at least secondary education. This is an expected finding and can be explained by an educated women's higher likelihood to be more informed about health risks and benefits which is then translated into demand for PNC services [11]. On the other hand, less educated women may not be knowledgeable about availability and accessibility of PNC services as well as how the health system operates [49]. Also, these lower educated women may have less say in decision-making about their health and this eventually affects PNC services uptake [59].

Moreover, this research revealed that religion is significantly associated with the use of PNC services with traditional and other believers having significantly lower levels of PNC utilization, which is consistent with the findings of a study by Ononokpono et al. [20]. This study finding may be explained by previous research's findings that reported on the traditional cultural practice of keeping newborns from the public due to fear of harm in the first month after their birth [56]. To increase the uptake of PNC services among this group, the involvement of religious leaders and home visits have been proposed by earlier studies $[56,60]$. This study suggests that the effect of religion on postnatal care use should be further investigated to better understand the underpinnings.

Finally, some sub Saharan African studies are consistent with this research that ethnicity is a significant predictor of PNC services utilization [20,61]. Ethnic groups are predominantly made up of people who share similar characteristics, and this has the potential to influence their perception about health and ultimately women's health seeking behavior [20,62].

One of the key goals of this study is to generate evidence that could be used to inform equity-based interventions. The conceptual framework for action on the social determinants of health proposed by the WHO Commission on Social Determinants of Health (CSDH) offers useful insights on addressing health inequities [63]. This framework considers the health system itself an intermediary determinant of health and hence exploring factors influencing access to health services is key to understanding and addressing health inequities. Our study indicates that the social determinants play-both at the individual and community levels- are key to addressing inequity in access to health care services, and inequities in health in turn.

\section{Study strengths and limitations}

This study contributes to the growing literature on the effect of community-level factors on the uptake of PNC services. Multilevel mixed modeling was used to ascertain the impact of community-level factors on the use of
PNC services, which is a more advanced approach to estimating the relationships than much of the available literature. Also, this study highlighted communities with a higher risk of not receiving PNC services for targeted interventions. Another significant strength of this research is the use of a large nationwide population-based dataset with a very high (97\%) response rate. Despite these strengths, there are limitations in interpreting the results. First, self-reported data can lead to information bias, which could affect accurate classification. Recall bias could be a concern; however, information on the women's PNC services use was restricted to 5 years preceding the survey and hence recall bias is probably not a major concern in this study. Also, medical need and information on quality of service received as well as cultural variables were not available in the secondary dataset of the 2014 GDHS. This study considered enumeration areas as communities, which may not necessary be representative of the actual communities because they have arbitrary boundaries. The 2014 GDHS lacked variables to examine the effect of travel time, quality of care, transportation system and cost of travel on the use of obstetric care services [24]. For this reason, only distance to a health facility was used in this research; relying on the response to the question of whether the distance to a health facility was either a "big problem or not a big problem" in the survey. Also, the GPS points taken in the 2014 GDHS were deliberately displaced randomly at a maximum of $2 \mathrm{~km}$ and $5 \mathrm{~km}$ in urban and rural communities respectively and seldom repositioning at random one GPS point by $12 \mathrm{~km}$ to ensure confidentiality and to conceal the identity of the respondents; so it is not probable that the findings from this study would be affected. Lastly, causality of the association cannot be inferred because a cross-sectional study design was used.

\section{Conclusions}

This study adds to the growing body of literature on the social determinants of health and our findings clearly point in the same direction as the CSDH framework for action on the social determinants of health. This framework asserts that addressing the structural upstream determinants of health, including inequities rooted in factors such as socioeconomic position, social class, education, and income is the most effective and sustainable approach to reducing health inequities. However, it is hardly surprising that it is much harder to address these upstream factors and hence, many of the interventions (action) to address inequities in health have focused on changing behaviors and not the roots of these healthseeking behaviors.

Based on our findings and consistent with the CSDH framework for action on the social determinants of health, factors such as income and education- both at 
the individual and community level- cannot be ignored if we hope to achieve real progress on improving equity in access to PNC services. Governments could choose different universal or targeted approaches to addressing inequities. Our findings regarding community level variation and the effect of community level factors indicate that it may not be sufficient to target subsidies to economically disadvantages women and tailor health messaging to women with lower education, community-level interventions are needed. Moreover, we identified hotspots of non-use of PNC services, concentrated in the Northern region that could be identified as priority intervention areas.

The findings also highlight the need to better understand the role of culture and religious beliefs in influencing access to PNC services; it is not possible to consider interventions to improve equity related to these factors without an in-depth understanding of factors using qualitative research. In addition, community-level variation also needs to be understood better in order to devise effective strategies to address community-based health inequities.

\section{Abbreviations \\ AIC: Akaike's Information Criterion; AOR: Adjusted odds risk; AUC: Area under the curve; BIC: Bayesian Information criterion; Cl: Confidence Interval; CSDH: Commission on Social Determinants of Health; GDHS: Ghana Demographic and Health Survey; GPS: Global positioning system; GSS: Ghana Statistical Service; ICC: Intraclass correlation coefficient; OR: Odds Ratio; PA: Population average; PNC: Postnatal care; ROC: Receiver operating characteristics; SD: Standard deviation; SE: Standard error; UOR: Unadjusted odds ratio; VIF: Variance Inflation Factor; VPC: Variance partition coefficient.}

\section{Acknowledgements}

We express sincere gratitude to MEASURE DHS for the availing the dataset that was used in this study.

\section{Authors' contributions}

All the authors contributed to all phases of the manuscript preparation and approval of final draft for submission. ED conceived of the study, took the lead role in conducting the analyses and writing the manuscript. ED and MF conceptualised and designed the research. CF and WZ supervised the statistical data analyses and interpretation of findings and significantly contributed to writing. SK and RL contributed to revising the analyses, interpretation of the results and writing. MF supervised developing the research questions, models, and the interpretations of the associated results as well as contributed to the writing of the paper.

\section{Funding}

This study received no funding.

\section{Availability of data and materials}

The study dataset is available in the MEASURE DHS repository, https://www. dhsprogram.com/data/dataset_admin/login_main.cfm. ${ }^{[G H I R 72 D T]}$

\section{Ethics approval and consent to participate}

The University of Saskatchewan ethical committee waived the need for ethical approval for the de-identified publicly available data that was used in this study.

\section{Consent for publication}

Not applicable.

\section{Competing interests}

The authors declare that they have no competing interests.

\section{Author details}

${ }^{1}$ School of Public Health, University of Saskatchewan, 104 Clinic Place, Saskatoon, SK S7N 2Z4, Canada. ${ }^{2}$ Department of Community Health and Epidemiology, Faculty of Medicine, Dalhousie University, Centre for Clinical Research, 5790 University Ave., Halifax, NS B3H 1V7, Canada. ${ }^{3}$ Department of Medicine, College of Medicine, Canadian Centre for Health and Safety in Agriculture (CCHSA), 104 Clinic Place, Saskatoon, SK S7N 2Z4, Canada. ${ }^{4}$ School of Nursing \& Health Studies, Georgetown University, 3700 Reservoir Rd, Washington, DC 20007, USA. ${ }^{5}$ School of Public Administration and Development Economics, Doha Institute for Graduate Studies, Al Tarfa Street, Zone 70, Doha, Qatar.

Received: 24 May 2020 Accepted: 17 December 2020

Published online: 07 January 2021

\section{References}

1. Sines E, Syed U, Wall S, Worley H. Postnatal care: a critical opportunity to save mothers and newborns. Policy Perspectives on Newborn Health. 2007: 1-7. https://cdn1.sph.harvard.edu/wp-content/uploads/sites/2413/2017/02/ snl_pncbrieffinal.pdf. Accessed 10 Mar 2019.

2. Warren C, Daly P, Toure L, Mongi P. Postnatal care opportunities for Africa newborn. Oxford: Oxford University; 2005

3. Ronsmans CHS, Stanton C. Socioeconomic differentials in caesarean rates in developing countries: a retrospective analysis. Lancet. 2006;368(9546):151623.

4. Shaw E, Levitt C, Wong S, Kaczorowski J, Group MUPR. Systematic review of the literature on postpartum care: effectiveness of postpartum support to improve maternal parenting, mental health, quality of life, and physical health. Birth. 2006;33(3):210-20.

5. You D, Hug L, Ejdemyr S, Beise J. Levels and trends in child mortality. Estimates developed by the UN Inter-agency Group for Child Mortality Estimation (IGME). Report; 2015. p. 2015.

6. WHO. Postnatal care for mothers and newborns. Highlights from the World Health Organization 2013 guidelines; 2015. p. 4.

7. GSS. Ghana Demographic and Health Survey 2014. In: Ghana Statistical Service (GSS), Ghana Health Service (GHS), and ICF International; 2015.

8. Aseweh Abor P, Abekah-Nkrumah G, Sakyi K, Adjasi CK, Abor J. The socioeconomic determinants of maternal health care utilization in Ghana. Int 」 Soc Econ. 2011;38(7):628-48.

9. GSS. Ghana multiple indicator cluster survey with an enhanced malaria module and biomarker with enhanced module biomarker. In: Ghana Statistical Service (GSS); 2011.

10. Kerber KJ, de Graft-Johnson JE, Bhutta ZA, Okong P, Starrs A, Lawn JE. Continuum of care for maternal, newborn, and child health: from slogan to service delivery. Lancet. 2007;370(9595):1358-69.

11. Titaley CR, Dibley MJ, Roberts CL. Factors associated with non-utilisation of postnatal care services in Indonesia. J Epidemiol Community Health. 2009; 63(10):827-31

12. Sakeah E, Aborigo R, Sakeah JK, Dalaba M, Kanyomse E, Azongo D, Anaseba D, Oladokun S, Oduro AR. The role of community-based health services in influencing postnatal care visits in the Builsa and the west Mamprusi districts in rural Ghana. BMC pregnancy and childbirth. 2018;18(1):295.

13. Agho KE, Ezeh OK, Issaka Al, Enoma Al, Baines S, Renzaho A. Population attributable risk estimates for factors associated with non-use of postnatal care services among women in Nigeria. BMJ Open. 2016;6(7):e010493.

14. Nuamah GB, Agyei-Baffour $P$, Mensah KA, Boateng D, Quansah DY, Dobin D, Addai-Donkor K. Access and utilization of maternal healthcare in a rural district in the forest belt of Ghana. BMC pregnancy and childbirth. 2019; 19(1):6.

15. Workineh $Y G$, Hailu DA. Factors affecting utilization of postnatal care service in Jabitena district, Amhara region, Ethiopia. Sci J Public Health. 2014;23: 169-76.

16. Prusty RK, Buoy S, Kumar P, Pradhan MR. Factors associated with utilization of antenatal care services in Cambodia. J Public Health. 2015;23(5):297-310.

17. Kurniati A, Chen C-M, Efendi F, Berliana SM. Factors influencing Indonesian women's use of maternal health care services. Health care for women international. 2018;39(1):3-18 
18. Fan X, Zhou Z, Dang S, Xu Y, Gao J, Zhou Z, Su M, Wang D, Chen G. Exploring status and determinants of prenatal and postnatal visits in western China: in the background of the new health system reform. BMC Public Health. 2018;18(1):39.

19. Bobo FT, Yesuf EA, Woldie M. Inequities in utilization of reproductive and maternal health services in Ethiopia. Int J Equity Health. 2017;16(1):105.

20. Ononokpono DN, Odimegwu CO, Imasiku EN, Adedini SA. Does it really matter where women live? A multilevel analysis of the determinants of postnatal care in Nigeria. Matern Child Health J. 2014;18(4):950-9.

21. Solanke BL, Amoo EO, Idowu AE. Improving postnatal checkups for mothers in West Africa: a multilevel analysis. Women \& health. 2018;58(2):221-45.

22. Worku AG, Yalew AW, Afework MF. Factors affecting utilization of skilled maternal care in Northwest Ethiopia: a multilevel analysis. BMC Int Health Hum Rights. 2013;13(1):20.

23. Mohan D, Gupta S, LeFevre A, Bazant E, Killewo J, Baqui AH. Determinants of postnatal care use at health facilities in rural Tanzania: multilevel analysis of a household survey. BMC pregnancy and childbirth. 2015;15(1):282.

24. Babalola S, Fatusi A. Determinants of use of maternal health services in Nigeria-looking beyond individual and household factors. BMC pregnancy and childbirth. 2009;9(1):43.

25. Jacobs C, Moshabela M, Maswenyeho S, Lambo N, Michelo C. Predictors of antenatal care, skilled birth attendance, and postnatal care utilization among the remote and poorest rural communities of Zambia: a multilevel analysis. Front Public Health. 2017;5:11.

26. Achia TN, Mageto LE. Individual and contextual determinants of adequate maternal health care services in Kenya. Women \& health. 2015;55(2):203-26.

27. Jat TR, Ng N, San Sebastian M. Factors affecting the use of maternal health services in Madhya Pradesh state of India: a multilevel analysis. Int J Equity Health. 2011;10(1):59

28. Yadav A, Kesarwani R. Effect of individual and community factors on maternal health care service use in India: a multilevel approach. J Biosoc Sci. 2016;48(1):1-19.

29. Solanke BL. Individual and community factors associated with indications of caesarean delivery in southern Nigeria: pooled analyses of 2003-2013 Nigeria demographic and health surveys. Health care for women international. 2018;39(6):697-716.

30. Ganle JK, Parker M, Fitzpatrick R, Otupiri E. Inequities in accessibility to and utilisation of maternal health services in Ghana after user-fee exemption: a descriptive study. Int J Equity Health. 2014;13(1):89.

31. Andersen R, Newman JF. Societal and individual determinants of medical care utilization in the United States. Milbank Mem Fund Q Health Soc. 1973; 51(1):95-124.

32. Andersen RM. Revisiting the behavioral model and access to medical care: does it matter? J Health Soc Behav. 1995:36(1):1-10.

33. Somefun OD, Ibisomi L. Determinants of postnatal care non-utilization among women in Nigeria. BMC research notes. 2016;9(1):21.

34. Huda TM, Chowdhury M, El Arifeen S, Dibley MJ. Individual and community level factors associated with health facility delivery: a cross sectional multilevel analysis in Bangladesh. PLoS One. 2019;14(2):e0211113.

35. Dankwah E, Kirychuk S, Zeng W, Feng C, Farag M. Socioeconomic inequalities in the use of caesarean section delivery in Ghana: a crosssectional study using nationally representative data. Int J Equity Health. 2019;18(1):162

36. Dankwah E, Zeng W, Feng C, Kirychuk S, Farag M. The social determinants of health facility delivery in Ghana. Reprod Health. 2019;16(1):101.

37. Kulldorff M, Nagarwalla N. Spatial disease clusters: detection and inference. Stat Med. 1995;14(8):799-810.

38. Kulldorff M. Geographic information systems (GIS) and community health: some statistical issues. Journal of Public Health Management and Practice. 1999:5(2):100-6

39. Aremu O, Lawoko S, Dalal K. Neighborhood socioeconomic disadvantage, individual wealth status and patterns of delivery care utilization in Nigeria: a multilevel discrete choice analysis. Int J Women's Health. 2011;3:167.

40. Bursac Z, Gauss CH, Williams DK, Hosmer DW. Purposeful selection of variables in logistic regression. Source code for biol Med. 2008;3(1):17.

41. Hosmer DWLS. Applied logistic regression. New York: Wiley; 2000.

42. Johnston $\mathrm{R}$, Jones K, Manley D. Confounding and collinearity in regression analysis: a cautionary tale and an alternative procedure, illustrated by studies of British voting behaviour. Qual Quant. 2018;52(4):1957-76.
43. Browne WJ, Subramanian SV, Jones K, Goldstein H. Variance partitioning in multilevel logistic models that exhibit overdispersion. J Royal Statistical Soc: Series A (Statistics in Society). 2005;168(3):599-613.

44. Merlo J, Chaix B, Ohlsson H, Beckman A, Johnell K, Hjerpe P, Råstam L, Larsen K. A brief conceptual tutorial of multilevel analysis in social epidemiology: using measures of clustering in multilevel logistic regression to investigate contextual phenomena. J Epidemiol Community Health. 2006; 60(4):290-7.

45. Maas CJ, Hox JJ. Sufficient sample sizes for multilevel modeling. Methodology. 2005;1(3):86-92.

46. Akaike H. A new look at the statistical model identification. In: Selected Papers of Hirotugu Akaike. Berlin: Springer; 1974. p. 215-22.

47. Darega B, Dida N, Tafese F, Ololo S. Institutional delivery and postnatal care services utilizations in Abuna Gindeberet District, west Shewa, Oromiya region, Central Ethiopia: a community-based cross sectional study. BMC pregnancy and childbirth. 2016;16(1):149.

48. Gayawan E. Spatial analysis of choice of place of delivery in Nigeria. Sexual \& Reproductive Healthcare. 2014;5(2):59-67.

49. Singh PK, Kumar C, Rai RK, Singh L. Factors associated with maternal healthcare services utilization in nine high focus states in India: a multilevel analysis based on 14385 communities in 292 districts. Health Policy Plan. 2013:29(5):542-59.

50. Tey N-P, S-I L. Correlates of and barriers to the utilization of health services for delivery in South Asia and sub-Saharan Africa. Sci World J. 2013;2013:111.

51. Onah HE, Ikeako LC, Iloabachie GC. Factors associated with the use of maternity services in Enugu, southeastern Nigeria. Soc Sci Med. 2006;63(7): 1870-8.

52. Ali AAA, Osman MM, Abbaker AO, Adam I. Use of antenatal care services in Kassala, eastern Sudan. BMC pregnancy and childbirth. 2010;10(1):67.

53. Chama-Chiliba CM, Koch SF. Utilization of focused antenatal care in Zambia: examining individual-and community-level factors using a multilevel analysis. Health Policy Plan. 2013;30(1):78-87.

54. Mezmur M, Navaneetham K, Letamo G, Bariagaber H. Individual, household and contextual factors associated with skilled delivery care in Ethiopia: evidence from Ethiopian demographic and health surveys. PLoS One. 2017; 12(9):e0184688.

55. Addai I. Determinants of use of maternal-child health services in rural Ghana. J Biosoc Sci. 2000;32(1):1-15.

56. Winch PJ, Alam MA, Akther A, Afroz D, Ali NA, Ellis AA, Baqui AH, Darmstadt GL, El Arifeen S, Seraji MHR. Local understandings of vulnerability and protection during the neonatal period in Sylhet District, Bangladesh: a qualitative study. Lancet. 2005;366(9484):478-85.

57. Anwar ISM, Akhtar N, Chowdhury ME, Salma U, Rahman M, Koblinsky M. Inequity in maternal health-care services: evidence from home-based skilled-birth-attendant programmes in Bangladesh. Bull World Health Organ. 2008;86:252-9.

58. Singh L, Rai RK, Singh PK. Assessing the utilization of maternal and child health care among married adolescent women: evidence from India. J Biosoc Sci. 2012:44(1):1-26.

59. Mosiur Rahman M, Haque SE, Sarwar Zahan M. Factors affecting the utilisation of postpartum care among young mothers in Bangladesh. Health \& Social Care Commun. 2011:19(2):138-47.

60. Pradhan Y, Upreti SR, Pratap KCN, Kc A, Khadka N, Syed U, Kinney MV, Adhikari RK, Shrestha PR, Thapa K. Newborn survival in Nepal: a decade of change and future implications. Health policy and planning. 2012;27(suppl_ 3):iii57-71.

61. Adu J, Tenkorang E, Banchani E, Allison J, Mulay S. The effects of individual and community-level factors on maternal health outcomes in Ghana. PLoS One. 2018;13(11):e0207942.

62. Ekman B, Axelson H, Ha DA, Nguyen LT: Use of maternal health care services and ethnicity: a cross-sectional analysis of Vietnam. Available at SSRN 9937132007

63. Solar O, Irwin A. A conceptual framework for action on the social determinants of health. In: WHO Document Production Services; 2010.

\section{Publisher's Note}

Springer Nature remains neutral with regard to jurisdictional claims in published maps and institutional affiliations. 